\title{
História pública e virtualidade: experiências de aprendizagem híbrida no ensino de História
}

\author{
Public History and Virtuality: Blended \\ Learning Experiences in History Teaching
}

Cláudia Regina Bovo*

Marcos Sorrilha Pinheiro ${ }^{\star *}$

\section{Resumo}

As tecnologias da informação alteraram a maneira como as sociedades organizam e compartilham saberes. De maneira implacável, colocaram em xeque instituições e agentes relacionados à produção e reprodução de conhecimentos, entre elas, a escola e o educador. Ao mesmo tempo, as formas como elaboram e armazenam memórias também sofreram mudanças, acarretando consequências ao historiador, até então, legítimo responsável pela organização da memória. Ciente de tais desafios, este artigo discute o uso de modelos de aprendizagem híbrida em sala de aula e a adoção da noção de história pública como estratégias para mitigar tais impactos na formação dos professores-historiadores. Além disso, apresentaremos algumas experiências desenvolvidas em nossas atividades docentes nas instituições de ensino onde atuamos, Unesp em Franca (SP) e Universidade Federal do Triângulo Mineiro (UFTM), em Uberaba (MG).

Palavras-chave: história pública; aprendizagem híbrida; ensino de história.

\section{Abstract}

Information technologies have changed the way societies organize and share knowledge. They relentlessly challenge institutions and agents responsible to create and reproduce knowledge, including a school and an educator. At the same time, the ways society produce and store memories also undergone profound changes, resulting in consequences for the historian, until now legitimate responsible for memory organizing. Aware of these matters, this article discusses the use of blended learning method in classroom and the adoption of the notion of public history as strategies to mitigate such impacts in the teachers-historians' formation. In addition, we present some experiences developed in our teaching activities in educational institutions with which we work, Unesp, Franca (SP) and UFTM, Uberaba (MG).

Keywords: public history; blended learning; history teaching.

\footnotetext{
* Universidade Federal do Triângulo Mineiro (UFTM), Uberaba, MG, Brasil. claubovo@yahoo.com

** Universidade Estadual Paulista (Unesp), Franca, SP, Brasil. marcos.sorrilha@gmail.com
} 
As tecnologias da informação deram novo ritmo à sociedade contemporânea ao introduzirem uma série de alterações nos seus processos de sociabilidade. Para além de suas ferramentas de maior interação social, de maneira geral, a democratização no acesso aos aparelhos celulares em sua versão smart mobile estabelece um novo padrão sobre a forma como produzimos e consumimos conhecimento. Nesse contexto, a Educação foi duplamente atingida, uma vez que se constitui enquanto um processo de socialização responsável por transferir os conhecimentos de uma dada comunidade para suas gerações mais novas.

Nesse sentido, existe uma preocupação relacionada à capacidade do modelo tradicional de educação - focado na figura da escola, da sala de aula e do professor - em conseguir promover o engajamento de seus alunos nas atividades de ensino-aprendizagem. Ao mesmo tempo, questiona-se a aptidão das instituições tradicionais de ensino para instruir seus alunos em um tipo de conhecimento que não estará obsoleto ao final do processo formativo. Se tomarmos os objetivos estabelecidos pela LDB para a educação em seu artigo segundo, é possível questionarmos se nosso sistema educacional é realmente capaz de promover "o pleno desenvolvimento do educando, seu preparo para o exercício da cidadania e sua qualificação para o trabalho" (LDB n. 9.394, de 20 dez. 1996, art. 2).

No quesito da cidadania, o que se percebe é a existência de um descompasso entre os modelos teóricos que sustentam a democracia liberal e o deficit de representação percebido pelos cidadãos em relação aos partidos e às instituições políticas (Rosanvallon, 2018). No campo do trabalho, não são poucos os estudos que apontam para um dado tão curioso quanto desesperador, segundo o qual se prevê que $85 \%$ das profissões que existirão em 2030 sequer foram criadas. ${ }^{1}$ Não por menos, professores e a escola parecem ter cada vez menor relevância na vida de seus estudantes. Em recente pesquisa realizada pela Google sobre o uso de sua plataforma de streamings de vídeos, o YouTube, quando questionados sobre quem são as pessoas que mais influenciam suas opiniões, nenhum dos usuários da rede social mencionou a figura do docente ou de instituições de ensino. ${ }^{2}$

No campo da história e de seu ensino, um agravante. $\mathrm{O}$ acesso às mídias digitais produtoras de conteúdo instantâneo altera também a forma como os seres humanos se relacionam com sua memória, tanto na elaboração de projetos de si, quanto no arquivamento de suas memórias. De acordo com Henry 
Rousso, vivemos a construção de um processo muito mais amplo que é a consolidação de uma globalização da memória, segundo o qual

assiste-se, assim, a um mesmo, para não dizer homogêneo, movimento planetário de reativação do passado, e podem-se observar, simultaneamente, numerosas semelhanças nas expectativas da opinião pública e nas políticas empregadas para dar um "justo" lugar à história e à memória em contextos aparentemente muito distantes uns dos outros. (Rousso, 2014, p. 267)

Ao orientar políticas públicas identitárias, essa nova etapa da elaboração global da memória impõe novos dilemas à prática e à escrita histórica e, correlatos a elas, inúmeros desafios se interpõem à formação de professores-historiadores. Essa nova era de acesso global à informação e de armazenamento de memórias vê crescer com vigor a dimensão do interesse público pelo passado, promovendo uma nova correlação de forças entre o historiador e novos atores midiáticos na disputa por seu objeto de ofício. Afinal, diferentemente do que vimos ocorrer após a Segunda Guerra Mundial, a produção e o gerenciamento da memória começam a se dar de maneira mais difusa, retirando da história ciência e do profissional historiador o seu posto de responsável preponderante e exclusivo da memória de uma comunidade. Em um modelo de formação e atuação profissional que perdurou até o presente momento, os profissionais da história se veem questionados não só pela narrativa histórica que produzem, mas também em sua atuação, na qualidade de educadores.

Para além dos jornais e das mídias tradicionais que sempre tiveram papel importante na formação da consciência histórica das populações, nos últimos anos novos espaços oriundos das mudanças impetradas pelo avanço tecnológico e dos meios de comunicação proporcionaram que indivíduos e grupos razoavelmente organizados tivessem um impacto gigantesco junto à opinião pública, por meio de sites, vídeos compartilhados por aplicativos de trocas de mensagens ou pela popularização de seus canais de vídeo e áudio em plataformas de streaming.

O resultado disso não foi apenas uma interferência na relação dos indivíduos com a consciência histórica nacional, mas, também, o questionamento da própria capacidade da historiografia em elaborar uma "história verdadeira" sobre o passado recente do Brasil. João Carlos Escosteguy Filho, ao refletir sobre as "Batalhas públicas pela história nas redes sociais", observa que "a novidade 
nessas batalhas interpretativas do passado foi a sua cada vez maior difusão por outros espaços midiáticos, notadamente as redes sociais, alçadas a novo espaço público de discussão que, aliás, influenciou decisivamente os rumos da política eleitoral nos dois últimos pleitos nacionais" (Escosteguy Filho, 2019, p. 41).

Aqui, a temática da cidadania, da legitimidade do professor e a influência dele sobre seus alunos se cruzam por caminhos tortuosos. Se a educação é o processo pelo qual se introduz as gerações mais novas aos símbolos e significados produzidos por uma dada comunidade, no que tange ao ensino de história o questionamento se volta para a capacidade do professor historiador em apresentá-las aos elementos centrais da memória de seus antepassados. Não por acaso, tais insatisfações redundaram em um amplo debate em torno da criação de instrumentos capazes de controlar que tipo de conteúdo os professores de história mobilizam em suas aulas, como foram (ou ainda são?) as propostas de projetos de lei em torno do Escola Sem Partido.

É justamente aqui, também, que o ensino de história e a escrita da história se encontram. Conforme buscaremos demonstrar neste artigo, a incorporação de uma concepção de história pública aos métodos de ensino e aprendizagem de história (especialmente na formação do professor-historiador), associada à elaboração de conteúdos para as redes sociais, pode ser um instrumento capaz de, ao menos, amenizar os descompassos evidenciados entre o universo escolar e o universo do aluno.

Provisoriamente, sintetizaremos como história pública aquilo que Miriam Hermeto definiu como uma "história na qual a ideia de 'autoridade compartilhada' é fundamental, reconhecendo a importância do papel do público em sua construção" (Hermeto, 2018, p. 153). Diante de uma sociedade que questiona a legitimidade de suas instituições de ensino, a noção de "autoridade compartilhada" parece fundamental para que haja uma aproximação dos conteúdos desenvolvidos em sala de aula com o interesse do aluno, bem como em sua relação com a memória e a história de sua comunidade.

\section{A TECNOLOGIA ASSOCIADA AOS PROCESSOS EDUCACIONAIS: UM CAMINHO SEM VOLTA}

A década de 1990 foi impactada pela chegada da internet aos lares das famílias ao redor do mundo. Antes um artefato destinado aos militares e, 
posteriormente, às universidades dos Estados Unidos da América, ela ganhou maior visibilidade com a criação do sistema World Wide Web (www), que tornou o ambiente de rede mais amigável a um público leigo e mais amplo. A partir daí o mundo entraria em um processo de aceleração da globalização, das trocas comerciais, informacionais e culturais (Castells, 2002).

Não foram poucos os autores das ciências sociais que se dedicaram a entender tal fenômeno, alguns de maneira entusiasta e outros em atitude temerária. No campo dos otimistas, destacamos o espanhol Manuel Castells e o francês Pierre Levy. Enquanto Castells em seu já clássico A sociedade em rede (2002) pensava nas possibilidades abertas para a mobilização política e a formação de grupos de resistência à coerção do Estado, Levy arriscava uma análise das transformações causadas no campo cultural e educacional. Segundo ele, entrávamos em um novo terreno da produção dos símbolos e significados humanos, numa mescla de virtualidade e realidade concreta que ele intitulou de cibercultura, nome que dá título ao seu livro mais famoso.

Em Cibercultura (1999), o argumento central de Levy era o de que a internet se configurava como um novo espaço de interação coletiva e experimentações, responsável pela produção de uma nova onda de descontextualização para a criação do conhecimento, colocando frente a frente humanos de várias partes do mundo com a cultura e a história dos demais pontos do globo. Vejamos:

A hipótese que levanto é a de que a cibercultura leva a copresença das mensagens de volta a seu contexto como ocorria nas sociedades orais, mas em outra escala, em uma órbita completamente diferente. A nova universalidade não depende mais da autossuficiência dos textos, de uma fixação e de uma independência das significações. Ela se constrói e se estende por meio da interconexão das mensagens entre si, por meio de sua vinculação permanente com as comunidades virtuais em criação, que lhe dão sentidos variados em uma renovação permanente. (Levy, 1999, p. 15)

Assim, os hiperlinks e os hipertextos tornavam ilimitada a maneira como os humanos absorveriam informações e formulariam novas interpretações sobre a vida e suas possibilidades. Era o fim do metadiscurso, da "autossuficiência dos textos", abrindo espaço para as interpretações particulares de 
mundo e da capacidade criativa de seus consumidores, resultado de um processo coletivo de trocas de saberes produzidos na rede.

Para explicar esse novo ambiente provocado pelo surgimento da internet, Levy recorreu a uma metáfora utilizada por Roy Ascott que fazia referência ao fenômeno das telecomunicações como sendo o segundo dilúvio. Viveríamos, então, uma espécie de dilúvio de informações, porém, diferentemente do que ocorrera na Bíblia, não haveria apenas uma arca, representante do metadiscurso, mas, sim, várias arcas, cada uma contendo as experiências e o conhecimento próprio de cada ser humano: "o fino enredamento dos humanos de todos os horizontes em um único e imenso tecido aberto e interativo gera uma situação absolutamente inédita e portadora de esperança [...]" (Levy, 1999, p. 14).

Para aquilo que nos interessa neste artigo, é importante informar que a dimensão pedagógica permeia toda a obra do francês. Desde o início, o autor entende que o ciberespaço é um lugar que promove a autonomia dos indivíduos dentro de uma concepção de educação ativa (aprender fazendo). Ao mesmo tempo, diante da impossibilidade de se produzir um metadiscurso, a função do professor, peça fundamental desse processo, deveria também se adaptar a uma nova realidade. Ao invés de ocupar o centro de difusão do saber, uma vez que o conhecimento estava disperso no ciberespaço, o educador deveria se portar como uma espécie de facilitador, aproximando o discente dos conteúdos ou, então, estabelecendo as conexões entre as várias arcas e seus saberes, assumindo um papel de "animador de inteligências coletivas" (Levy, 1999, p. 158).

Cibercultura foi publicado no final da década de 1990 e, por isso, vislumbrava um mundo que ainda não sabíamos para onde iria, cheio de esperança e de uma boa dose de ingenuidade. No entanto, algumas proposições feitas ao modelo educacional ainda soam bastante promissoras e ganham espaço junto às comunidades acadêmicas nos dias atuais. Para seu autor, a educação do futuro deveria passar por duas grandes reformas. A primeira delas era a aplicação de dispositivos e do espírito da Educação a Distância $(\mathrm{EaD})$ ao cotidiano educacional; e a segunda passava pelo reconhecimento das experiências adquiridas pelos alunos fora do ambiente escolar, produzindo uma quebra no monopólio da escola enquanto um ambiente de transmissão e construção do conhecimento. Conforme Levy entendia, as instituições de educação formal passariam a ser um polo de convergência de saberes virtuais. Explicita-se: 
as ferramentas do ciberespaço permitem pensar vastos sistemas de testes automatizados acessíveis a qualquer momento e em redes de transações entre oferta e procura de competência. Organizando a comunidade entre empregadores, indivíduos e recursos de aprendizagem de todos os tipos, as universidades do futuro contribuiriam assim para a animação de uma nova economia do conhecimento. (Levy, 1999, p. 158)

No que diz respeito à EAD, desde que Levy arriscou suas primeiras formulações, muitos trabalhos foram desenvolvidos na tentativa de se produzir um tipo de ensino fundamentado em um modelo ativo, voltado para os interesses do aluno e, ao mesmo tempo, incorporando elementos tecnológicos às estratégias de aprendizagem. Esse espírito da Educação a Distância da qual ele falava, de mesclar a busca pelo conhecimento nas redes tendo o professor como uma espécie de guia, é o que vem sendo chamado de aprendizagem híbrida (blended learning).

Em artigo publicado com o intuito de checar a aplicabilidade de sistemas híbridos nas universidades, Lara Martins e Thaís Zerbini explicam que "os contextos virtuais promovem e requerem o desenvolvimento de habilidades para uma aprendizagem mais independente e flexível, considerando tempo, espaço e ritmo do aprendiz por meio de um conjunto de recursos didáticos adaptados às tecnologias e múltiplas mídias" (Martins; Zebrini, 2014, p. 317 318). Segundo defendem as autoras, a incorporação de tais ferramentas às estratégias de aprendizado possui uma dupla função, pois, ao mesmo tempo que respeitam o ritmo do aluno e suas possibilidades de instrução fora do ambiente escolar, estimulam o desenvolvimento de habilidades e competências de planejamento, de forma que ele possa regular e avaliar seus próprios recursos de aprendizagem.

É importante lembrar que a aprendizagem híbrida não tem um modelo pronto, podendo resultar em diferentes estratégias a serem adotadas por professores segundo suas necessidades e criatividade. Entre algumas experiências, aquela que ganhou mais estudos e desenvolve uma espécie de metodologia é o modelo de Sala de Aula invertida (flipped classroom). Trata-se de uma proposição nascida da experiência de dois professores estadunidenses, Jonathan Bergmann e Aaron Sams, que se converteu em um livro no ano de 2012 com o sugestivo título Flip Your Classroom: Reach Every Student in Every Class Day. 
Em 2016, o trabalho ganhou uma versão brasileira com nome mais técnico, Sala de aula invertida: uma metodologia ativa de aprendizagem.

A ideia, nascida ainda no ano de 2007, fruto da necessidade específica de alguns estudantes que não podiam comparecer às aulas dos dois professores de química, é bastante simples: "basicamente, o conceito de sala de aula invertida é o seguinte: o que tradicionalmente é feito em sala de aula, agora é executado em casa, e o que tradicionalmente é feito como trabalho de casa, agora é realizado em sala de aula" (Bergmann; Sams, 2016, p. 11).

De maneira resumida, podemos dizer que segundo essa proposição, por meio de vídeos, podcasts e textos, entre outros recursos, os alunos ganham acesso ao conteúdo da disciplina fora da sala de aula, podendo estudá-lo de acordo com o seu tempo ou no momento em que melhor lhes convier, pausando ou rebobinando o professor quando acharem desejável (Bergmann; Sams, 2016, p. 21). Além disso, os horários presenciais do curso são usados pelos professores para abordar os assuntos com um nível mais profundo de reflexão, debater possíveis dúvidas, aplicar exercícios, elaborar trabalhos em grupos relacionando-os aos conteúdos disponibilizados on-line ou compartilhar experiências relacionadas aos desafios da profissão, no caso do ensino superior.

Com isso, a inversão da ordem da sala de aula provoca obrigatoriamente uma revisão na própria função atribuída ao professor. Conforme destacam os autores:

Deixamos de ser meros transmissores de informações; em vez disso, assumimos funções mais orientadoras e tutoriais. [...] Um dos grandes benefícios da inversão é o de que os alunos que têm dificuldade recebem mais ajuda. Circulamos pela sala de aula o tempo todo, ajudando os estudantes na compreensão de conceitos em relação aos quais se sentem bloqueados. (Bergmann; Sams, 2016, p. 11-12)

Em outros termos, o professor deixa de ser o centro do processo educativo, encarando o momento presencial do encontro em sala de aula não mais como um ato de transmissão do conhecimento, mas como um local de socialização. Assim, o educador abandona a figura tradicional do sábio dos palcos e assume um papel de tutoria ou guia de aprendizado, semelhante ao animador de inteligências sugerido por Levy. O mesmo podemos dizer em relação aos 
alunos que passam a desempenhar funções mais ativas no desenvolvimento das habilidades dentro da sala de aula, desenvolvendo maior autonomia e comprometimento com sua instrução e formação.

Esse modelo também está em consonância com a segunda reforma indicada por Levy, uma vez que reconhece os saberes adquiridos pelos alunos de maneira independente, fora do ambiente escolar, e aceita que as instituições de ensino não mais detêm o monopólio do saber. Nesse ponto, Bergmann e Sams estão em acordo com o filósofo francês, conforme podemos observar:

os alunos de hoje crescem com acesso à internet, YouTube, Facebook, MySpace e a muitos outros recursos digitais. Em geral, podem ser vistos fazendo os exercícios de matemática enquanto enviam mensagens de texto, postam e curtem no Facebook e ouvem música, tudo ao mesmo tempo. Muitos desses estudantes relatam que quando chegam à escola precisam se desconectar e emburrecer, já que as escolas proíbem telefones celulares, iPods e quaisquer outros dispositivos digitais. O mais triste é o fato de que a maioria dos alunos carrega consigo dispositivos de computação mais poderosos do que grande parte dos computadores existentes em nossas escolas subfinanciadas - e ainda não lhes permitimos explorar esses recursos, que são naturalmente parte de seu dia a dia. (Bergmann; Sams, 2016, p. 18)

Ao negar aos seus alunos o acesso às tecnologias que compõem seu cotidiano, a escola acaba sendo vista por eles como um ambiente anacrônico, sem sintonia com suas demandas e com um mundo que lhes cobra cada vez mais domínio de tais ferramentas. Além disso, colocam em xeque sua legitimidade e abrem o questionamento sobre sua capacidade de apresentar ao aluno um número de informações atualizadas sobre determinados assuntos. Permitir que o aluno busque o conhecimento fora da sala de aula e o reconheça como um conteúdo válido a ser trabalhado pelo professor junto dos demais colegas de sala é, também, uma forma de a escola valorizar o universo de referências de seu educando e reconhecer que não tem mais o monopólio do saber, entendendo-se como "um polo de convergência de saberes virtuais". De outro modo, como bem observam os autores,

Em uma época em que parte da comunidade não confia na educação, a inversão abre as portas da sala de aula e permite a entrada do público. Nossos vídeos são 
postados na internet, e os pais dos alunos e outras partes interessadas têm livre acesso ao material didático. Em vez de ficarem em dúvida sobre o que os alunos estão aprendendo na escola, os pais têm acesso às nossas lições com apenas alguns cliques. (Bergmann; Sams, 2016, p. 28)

Esse reconhecimento não significa que qualquer saber é importante ou que conteúdos não científicos devam pautar as discussões de uma disciplina, mas que a escola reconhece as transformações pelas quais passamos, compreende que os modelos hierárquicos estão em constante mudança, e que a educação tem um interesse público cada vez maior. Além disso, dar visibilidade ao que se produz dentro do ambiente escolar e acadêmico é fundamental nessa etapa em que nos inserimos.

Como sabemos, o mundo construído pelas tecnologias levou vários autores de diversas áreas das ciências sociais a formularem interpretações sobre o novo modelo de sociedade que então surgia. Conceitos como modernidade líquida (Bauman, 2001), sociedades rizomáticas (Morin, 2000) ou as diversas variações elaboradas em torno da temática da diversidade demonstram uma percepção comum de que o mundo contemporâneo não tem mais espaço para paradigmas perenes ou fundamentados em figuras mononucleares de autoridade, de legitimidade ou saber.

Neste ponto, propor um modelo de educação que se mescla com os saberes apreendidos pelos alunos fora dos espaços tradicionais de ensino é uma maneira de atualizar as estratégias de aprendizagem e conceber a educação como um processo definitivamente público. Público não no sentido do Estado, mas no sentido em que ela se concretiza em espaços públicos de compartilhamento de memórias e conhecimentos, como o museu, as bibliotecas, os monumentos, as praças e, também, a internet e suas inúmeras redes sociais.

\section{A HISTÓRIA PÚBLICA: UM CAMINHO PARA A APRENDIZAGEM HÍBRIDA}

Dentro dessa concepção de educação pública voltada para um mundo de conexões, o ensino de História tanto para a formação inicial de professores-historiadores quanto para a educação histórica das sociedades tem muito a ganhar com a incorporação dos debates advindos da história pública. Isso porque a noção de "autoridade compartilhada" surgida nesta seara é uma 
resposta inovadora que se integra totalmente às propostas educacionais da aprendizagem híbrida e da sala de aula invertida.

O interessante é que o uso desse termo, "autoridade compartilhada" (shared authority) aparece pela primeira vez mobilizado por Michael Frisch (1990), em sua obra A Shared Authority: Essays on the Craft and Meaning of Oral and Public History, do início da década de 1990. Fruto de um trabalho que buscava contextualizar os debates sobre autoria na pesquisa baseada em depoimentos orais, Frisch se propôs a refletir sobre o papel do historiador como único autor ativo no processo de interpretação dos depoimentos orais utilizados como evidências históricas. De um jogo de palavras com a noção de autoria, o conceito de "autoridade compartilhada" provocou muitos historiadores, desdobrando-se em uma revelação inconveniente que assombrava suas consciências. Como informou o próprio Frisch (2016), a "autoridade compartilhada" não era seu objeto, mas ganhou vida como resposta possível ao processo de conscientização da prática historiográfica em si.

Atualmente, o conceito de "autoridade compartilhada" tem se confundido com um princípio ético sobre como conduzir a produção da história. Em tempos nos quais o mundo conectado desdobra-se em debates sobre acesso democrático à informação e torna corrente o uso da palavra compartilhar, quando diferentes meios sociais questionam o monopólio do historiador e dos professores de história enquanto intérpretes do passado, a noção de "autoridade compartilhada" pode canonizar-se como um mandamento sobre o potencial que reside no debate de inúmeras vozes não hierarquicamente ordenadas.

Nesse sentido, podemos afirmar que os ensaios de Frisch e a recepção em torno deles originaram uma inflexão fundamental para lidar com os diferentes modos de interpretar as experiências humanas que passam pela baliza do tempo, mesmo quando assumem discursos excludentes entre si. Assim, a noção de "autoridade compartilhada" pode, de modo geral, promover o encontro entre a consciência histórica científica e as consciências históricas das populações, suscitando que o professor-historiador em formação não relegue a segundo plano o conhecimento histórico de suas audiências ou leitorados. Para isso, aproximar-se do debate da história pública é fundamental.

Beatriz Sarlo (2007) chama a história pública de "história da grande circulação", uma modalidade não acadêmica de produção de narrativas históricas que tem grande incidência sobre a consciência histórica das populações: 
a história de grande circulação é sensível às estratégias com que o presente torna funcional a investida do passado e considera totalmente legítimo pô-lo em evidência. Se não encontra respostas na esfera pública atual, ela fracassa e perde todo o interesse. A modalidade não acadêmica (ainda que praticada por um historiador de formação acadêmica) escuta os sentidos comuns do presente, atende às crenças de seu público e orienta-se em função delas. Isso não a torna pura e simplesmente falsa, mas ligada ao imaginário social contemporâneo, cujas pressões ela recebe e aceita mais como vantagem do que como limite. (Sarlo, 2007, p. 13)

Além dessa definição mais clássica, que toma a história pública como discurso ou narrativa histórica produzida ou assumida naquilo que se convencionou chamar de cultura histórica das sociedades, temos também ligada à expressão a ideia de acesso irrestrito às documentações e narrativas históricas. Desde 1970, uma grande quantidade de arquivos antes fechados ao acesso de pesquisadores e do grande público, como os arquivos dos documentos governamentais das ditaturas latino-americanas e os arquivos do Vaticano, tornaram-se acessíveis. Com o consequente processo de digitalização de fontes manuscritas e divulgação em larga escala de documentos históricos promovidos pelo desenvolvimento tecnológico, a história vem se tornando cada vez mais pública.

Segundo Sara Albieri,

A expressão "história pública" pode ser entendida de várias maneiras. De imediato, ela evoca a ideia de acesso irrestrito, isto é, de um conhecimento histórico franqueado a todos. Especialmente em nossos dias, entende-se que clausuras serão abertas e que informações, antes censuradas ou veladas, doravante ocuparão espaços de domínio público. (Albieri, 2011, p. 19)

Enquanto um campo de estudo historiográfico, a história pública se interessa por compreender como as histórias são construídas e interpretadas por uma comunidade mais ampla. Ela não tem uma definição única, mas, de forma geral, pode ser descrita como a prática da história por historiadores com formação acadêmica trabalhando para agências públicas, universidades ou para grupos e associações fora do ambiente universitário. Historiadores públicos estudam fenômenos como as transformações de comemorações de datas 
históricas, debates sobre monumentos históricos, a maneira como certas famílias e grupos são lembrados ou esquecidos. Os estudos sobre memória, consciência histórica, historiografia e ensino de história são fundamentais para compreender a dimensão pública da história.

Para além de uma teoria, a história pública é uma prática: é uma maneira de se fazer história para e com o público. Essa prática é informada pela história disciplinar produzida nas escolas e universidades, mas tem como objetivo alcançar e se engajar com a comunidade mais ampla debatendo cultura, fornecendo serviços e facilitando o acesso à informação. Isso pode ser feito de formas variadas, como exposições, planos patrimoniais, podcasts e produção de mídias para redes sociais, mas também pela incorporação do debate sobre o resultado da informação ou conhecimento histórico mobilizado nesses tipos de mídias e espaços.

Dessa maneira, a história pública passa a ser vista então como um fenômeno que trata diferentes produções históricas extracientíficas como objeto de estudo e, sobretudo, de debate, com a finalidade de encontrar sua contribuição para formação histórica das populações. Em sintonia com os debates sobre o desenvolvimento da educação histórica proposta por Jörn Rüsen, ${ }^{3}$ a história pública está em intensa articulação com o papel atribuído à história na formação social dos sujeitos, da mesma maneira que se apresenta como um caminho para a aprendizagem híbrida. Afinal, parece-nos que a aprendizagem híbrida e a história pública dispõem da mesma essência: ambas compartilham a autoridade no processo de construção do saber e consideram o conhecimento do público para a elaboração de suas estratégias de aprendizagem.

\section{Aprendizagens HÍBRIDAS EM AÇÃO}

Movidos por tais preocupações e inquietações, desde 2018 resolvemos aplicar alguns desses conceitos à sala de aula, visando uma formação mais autônoma para os professores-historiadores em formação, bem como o contato com essa metodologia da aprendizagem híbrida para que pudessem considerá-la em sua futura atuação profissional. Todas as experiências foram feitas em disciplinas dos cursos de licenciatura em história na Universidade Estadual Paulista (Unesp), em Franca (SP), e na Universidade Federal do Triângulo 
Mineiro (UFTM), em Uberaba (MG), onde atuamos respectivamente como docentes efetivos.

No caso da Unesp, o método de sala de aula invertida não foi plenamente aplicado, ainda que parte da dinâmica da sala de aula tenha sido transferida para ambientes virtuais de aprendizagem, tanto o Google Classroom quanto plataformas de streaming, como o YouTube. Em 2018 e 2019, tais estratégias foram aplicadas nas disciplinas de História dos Estados Unidos da América e História da África, com alguma variação a cada semestre, observando novas possibilidades abertas com a experiência adquirida ou, então, testando novas ideias e alternativas. Ao longo dos 2 anos foi possível pensar em um modelo mais bem acabado, baseado em experiências que funcionaram com maior resultado, conforme comentaremos adiante.

$\mathrm{Na}$ Unesp, em todos os casos foram criadas salas de aulas virtuais no Google Classroom, ferramenta gratuita disponível em multiplataforma que pode ser acessada tanto de computadores quanto de celulares. Nesse ambiente, os alunos tinham acesso a um material complementar após cada nova aula, composto não apenas por materiais previamente selecionados como, também, por produtos mencionados e/ou sugeridos pelos alunos. Quando um tema não previsto na preparação do curso tomava parte importante da aula, um novo arquivo era inserido junto ao material de apoio para que todos os alunos tivessem acesso ao conteúdo. Com alguma alteração, o material de apoio foi composto por uma mídia audiovisual (vídeos, documentários, canais de YouTube ou podcasts), um texto acadêmico, uma matéria em site ou jornal de grande circulação e os slides de PowerPoint utilizados pelo professor ou por algum grupo de seminário.

Vale lembrar que o Google Classroom tem ferramentas de interação entre aluno e professor que permitem o envio individual e sigiloso de atividades, com espaço para a postagem de feedbacks personalizados sobre a correção de cada trabalho, bem como a notificação imediata da nota do aluno naquele exercício. Assim, no decorrer da disciplina, o discente já tomava ciência de seu desempenho, no envio tanto de resenhas e/ou resumos de documentos, filmes ou outros artigos, como de sua atuação em seminários presenciais. Além disso, também é possível elaborar questionários com respostas em múltiplas escolhas com temas relacionados à disciplina, aumentando o engajamento dos alunos. 
Figura 1 - Exemplo de material didático - História dos Estados Unidos e História da África

$\equiv$ Google Sala de aula

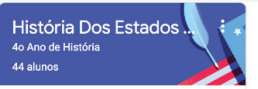

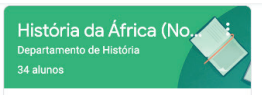

34 alunos
História da África (Di.. Departamento de Historia 40 alunos

Outra estratégia utilizada apenas no ano de 2019, na disciplina de História dos Estados Unidos, foi a elaboração de um canal no YouTube onde o professor postou comentários gerais sobre cada aula, recapitulando conteúdos trabalhados e respondendo às dúvidas que eram encaminhadas ao final da aula presencial ou por meio do Google Classroom. Intitulado de "Arremate de Ideias", esse foi um mecanismo interessante por alguns motivos que comentaremos a seguir. ${ }^{4}$

O primeiro está relacionado a uma maior interação do professor com o aluno, podendo atender alunos com dificuldades de compreensão das aulas e, ao mesmo tempo, socializar suas dúvidas com os demais colegas sem serem expostos. O segundo diz respeito aos discentes que não puderam comparecer presencialmente e passaram a ter um comentário geral do professor sobre os temas abordados em sala de aula. Alguns alunos relataram que ouviam as aulas durante o transporte de volta à sua casa ou, então, tornavam a assisti-las após fazerem a leitura dos textos de apoio. Por último, alertados por um grupo de discentes, tais vídeos foram disponibilizados de forma pública no YouTube para que outras pessoas pudessem ter acesso a esse tipo de conhecimento produzido nos ambientes universitários. Em termos de alcance, não é possível dizer que isso teve algum tipo de êxito, porém, trata-se de uma ideia que pode ser mais bem explorada no futuro, adequando o conteúdo produzido às métricas e tendências daquela rede social. Neste ponto, é possível dizer que a disciplina cumpriu o seu primeiro compromisso com a história pública, uma vez que partilha da "ideia de acesso irrestrito, isto é, de um conhecimento histórico franqueado a todos" (Albieri, 2011, p.19).

Porém, a relação da disciplina com a concepção de história pública também se concretizou no âmbito da elaboração do método de avaliação. 
Tradicionalmente, tínhamos por costume dividir a avaliação em três estágios: a participação do aluno em seminários; a elaboração de resenhas de filmes e fontes históricas relacionadas a cada disciplina e, por fim, a confecção de um artigo relacionado a alguns dos temas abordados em sala de aula. Nestes 2 anos, porém, substituímos o artigo final pela produção de mídias digitais. Assim, os alunos estavam livres para se aproximarem das mídias com as quais tivessem mais familiaridade e algum tipo de empatia, onde produziriam um conteúdo que pudesse ser compartilhado com um público mais amplo. Surgiram assim alguns blogs, ${ }^{5} \operatorname{vogs}$, perfis de Instagram, ${ }^{6}$ contas no Twitter, ${ }^{7}$ fanpages no Facebook, ${ }^{8}$ canais de YouTube ${ }^{9}$ e podcasts, ${ }^{10}$ entre outros. Aqueles mais tímidos, voltados às letras, poderiam se arriscar nos blogs, ao passo que os mais extrovertidos apelaram para mídias mais interativas, com apelo audiovisual.

O grande acerto dessa atividade foi o de deixar o tema livre. Desde que relacionados à História dos Estados Unidos da América ou da África e tendo um caráter pedagógico/informativo, os alunos poderiam abordar qualquer assunto ou tema, compartilhando entre estudantes e professor a autoridade sobre a importância dos assuntos da disciplina. Isso possibilitou que os discentes investissem em temáticas de seu universo de interesse, explorando as possibilidades de estudo e pesquisa naquele assunto e, ao mesmo tempo, completando sua formação com conteúdos que não puderam ser contemplados no plano do curso. Assim, ao longo do semestre os discentes se organizaram, individualmente ou em grupo, para elaborar suas mídias, escolher a plataforma com que tivessem mais intimidade e eleger um tema para trabalharem. Muitos optaram por produzir conteúdos voltados para a discussão de gênero, ${ }^{11}$ etnia, ${ }^{12}$ música, drogas, ${ }^{13}$ cinema, ${ }^{14}$ esportes ${ }^{15}$ e conteúdo infantil,,${ }^{16}$ entre outros.

Pensamos que um modelo mais bem estabelecido a ser aplicado em oportunidades futuras deva focalizar a produção de vídeos de até 30 minutos que abordem os conteúdos prévios de cada aula e outros (menores) que explorem alguns assuntos e dúvidas surgidos em aula. Como sugerem Bergmann e Sams (2016, p. 13), na primeira parte da aula discutiríamos o vídeo e os textos indicados para o dia, levantando as dúvidas dos alunos, podendo ser enviadas previamente pelo Google Classroom. A segunda parte das atividades presenciais seria dedicada à elaboração e ao desenvolvimento do projeto. As resenhas de 
filmes e fontes históricas seriam mantidas para que outras dimensões da aprendizagem, como a escrita do texto histórico, possam ser medidas.

Na UFTM, desde 2014, todas as disciplinas obrigatórias da formação geral em história têm uma carga horária de prática como componente curricular (PCC), correspondente a 30 horas. Foi pensando na finalidade das PCCs ${ }^{17} \mathrm{e}$ nessa carga horária significativa que desenvolvemos uma estratégia para articular os debates da história pública à aprendizagem híbrida, a fim de estimular os estudantes, futuros professores-historiadores, a considerarem a diversidade de narrativas históricas presentes nas redes sociais e seu potencial como recurso para aprendizagem histórica de qualquer pessoa.

De acordo com Isabel Barca (2001, p. 13-14), os estudos de referência sobre educação histórica iniciados nos anos 1980 demonstraram que os alunos da Educação Básica - e, acrescentamos, também do Ensino Superior - dão sentido aos acontecimentos históricos a partir da utilização de conceitos fornecidos pelas suas vivências. Assim, a forma como elaboram os conceitos históricos está imediatamente relacionada aos conceitos da vida social que experimentam enquanto sujeitos. Por isso, trazer para o debate as narrativas produzidas pela história pública era tão importante. O desejo de trabalhar com história pública também surgiu alicerçado na demanda dos próprios estudantes, que a partir de 2018 denunciavam o esgotamento do modelo da PCC que solicitava exclusivamente a análise de materiais didáticos ou produções de planos e projetos de ensino para salas de aula fictícias da Educação Básica.

Nesse sentido, usamos a carga horária da PCC para orientar/tutorar os estudantes na produção de conteúdos para diferentes plataformas de mídias sociais (canais de YouTube, páginas de Facebook, perfis no Instagram, perfis no Twitter e blogs), com foco exclusivo nos temas relacionados ao debates historiográficos propostos pela disciplina obrigatória ministrada, no caso História Medieval. Primeiramente, eles precisavam buscar, a cada aula, os temas abordados historiograficamente em sala nas diferentes plataformas de mídias sociais. Numa tentativa de mapear as narrativas de divulgação científica da Idade Média e abordagens da cultura histórica sobre os medievalismos contemporâneos, estimulamos o encontro de textos historiográficos definidos por nós com as diferentes narrativas produzidas pelas mídias sociais trazidas pelos estudantes. 
Além disso, como um dos mecanismos de avaliação, os estudantes precisavam produzir ao longo do semestre letivo conteúdos digitais sobre temáticas da Idade Média qualificáveis a partir de parâmetros historiográficos para uma das plataformas de rede social à sua escolha. Em termos efetivos, os estudantes tenderam a optar pelas redes sociais das quais faziam uso mais constante. Vimos nascer muitas threads em perfis de Twitter, ${ }^{18}$ alguns canais de YouTube,${ }^{19}$ algumas páginas de Facebook ${ }^{20}$ e dezenas de perfis no Instagram, ${ }^{21}$ que demonstraram o desenvolvimento de uma linguagem acessível da História Medieval, ao mesmo tempo que estimularam a iniciativa dos estudantes a buscar aprofundamento em temáticas não previstas inicialmente no plano de ensino da disciplina, ${ }^{22}$ da mesma forma que se deu com os alunos da Unesp.

Hoje a questão primordial sobre a formação em história, seja ela na Educação Básica ou no Ensino Superior, não está mais no tipo de conteúdos a trabalhar, mas em considerar como se dá o processo cognitivo de aquisição do conhecimento histórico e as relações que se fazem entre esse conhecimento específico, acadêmico, e o conhecimento construído em outros espaços onde reverbera a história pública das comunidades. Obviamente, não podemos prescindir de uma seleção de temas a serem trabalhados em sala de aula, nem ignorar temáticas consideradas clássicas para o pensamento historiográfico, mas essa seleção de conteúdos não deve ser entendida como a única possibilidade e finalidade para a formação histórica.

Um dos comportamentos resultantes das estratégias de aprendizado empregadas tanto na Unesp quanto na UFTM, e que mais nos chamou a atenção, foi o fato de, cada vez mais, os estudantes nos procurarem ao final das aulas ou em horários agendados para perguntarem sobre como deveriam proceder com suas mídias ou sobre os conteúdos que deveriam abordar em sua criação. Nesse ponto, percebemos que os autores Bergmann e Sams (2016) têm razão quando afirmam que o momento "face a face" em sala de aula deve ser entendido como momento de tutoria, explorando mais a socialização entre professores e alunos e desperdiçando menos tempo com a exposição, muitas vezes enfadonha, de conteúdos. Da mesma forma, coloca-nos em sintonia com a concepção de animadores de inteligência defendida por Levy (1999).

Fazendo um balanço dessas experiências, está cada vez mais nítido que a orientação para produção de conteúdos digitais de histórias não deve ser encarada apenas como uma avaliação, mas sim, convertida em um projeto a ser 
desenvolvido com metas e prazos, utilizando o horário de aula presencial para a montagem de um cronograma e orientação dos alunos em cada etapa. De maneira geral, a tendência por nós observada é que as disciplinas terminem sua migração pra o modelo de sala de aula invertido, explorando, cada vez mais, o momento presencial para dialogar com os alunos, auxiliando na produção de mídias que efetivamente atinjam um número maior de pessoas. Além disso, é possível pensar na elaboração de uma plataforma que agregue todas essas experiências e sirva como material de apoio para que professores do Ensino Básico empreguem em suas disciplinas. ${ }^{23}$

\section{CONSIDERAÇÕES FINAIS}

Ao trazermos a concepção de história pública para dentro da sala de aula, buscamos fazer do aluno corresponsável por sua formação na medida em que os produtos elaborados no ambiente de aprendizagem partem do seu universo de expectativas e de assuntos vinculados a uma determinada disciplina e/ou conteúdo em que ele escolheu se aprofundar. Ao mesmo tempo, isso provê à sua atividade um sentido que extrapola os limites dos muros escolares, possibilitando que ele compartilhe com outros membros de sua comunidade os conhecimentos por ele produzidos.

Como observou Meg Foster (2014), as novas tecnologias aceleram o domínio público sobre a história. Pessoas comuns têm acesso a bases de dados de documentos on-line, dos quais retiram referências para produzir interpretações e disseminá-las livremente por meio de ferramentas tecnológicas, como blogs e redes sociais. Ausentar-se do debate com esse tipo de produção histórica é não perceber a dimensão que a história possui para a sociedade. Em tempos de questionamento da utilidade das ciências humanas e sociais, a produção independente desse tipo de conteúdo deixa evidente a importância que a história tem na organização dos mecanismos de interpretação da vida social. Nesse sentido, é preciso reconhecer nesses espaços lugares legítimos de se empreender a operação historiográfica, integrando definitivamente o debate da história feita pelo público e de seus mecanismos de difusão na formação de professores-historiadores.

Considerando especificamente a formação do profissional da história, vemos ainda uma vantagem extra na adoção dessa estratégia. Diante de um 
mercado de trabalho que muitas vezes limita a atuação do licenciado ao espaço da sala de aula, ao desenvolver novas habilidades e expertises, bem como o domínio de novas tecnologias, ele se torna capaz de buscar campos diversificados de atuação. Seguindo um maior interesse do público pelo consumo de história ou pela elaboração de novos projetos de memória, esse professor-historiador pode se colocar de maneira bem posicionada no mercado, ${ }^{24}$ concebendo a elaboração de conteúdos de história para as redes sociais sob uma perspectiva pedagógica - afinal, esse é o espírito da história pública.

\section{REFERENNCIAS}

ALBIERI, Sara. História pública e consciência histórica. In: ALMEIDA, Juniele R. de; ROVAI, Marta G. de Oliveira (org.). Introdução à História Pública. São Paulo: Letra e Voz, 2011. p. 19-28.

BARCA, Isabel. Educação histórica: uma nova área de investigação. História, Revista da Faculdade de Letras, Porto, III série, v. 2, p. 13-21, 2001.

BAUMAN, Zygmunt. Modernidade líquida. Rio de Janeiro: Zahar, 2001.

BERGMANN, Jonathan; SAMS, Aaron. Sala de aula invertida: uma metodologia ativa de aprendizagem. Rio de Janeiro: LTC, 2016.

BRASIL. Lei de Diretrizes e Bases da Educação Nacional. Lei 9394, de 20 dez. 1996. Disponível em: http://www.dca.fee.unicamp.br/ leopini/consu/reformauniversitaria/ldb.htm. Acesso em: 25 nov. 2019.

CAFARDO, Renata. Professores youtubers, edutubers atraem 5 milhões para aulas fora da escola. O Estado de S. Paulo, 28 nov. 2019. Disponível em: https://educacao. estadao.com.br/noticias/geral,professores-youtubers-edutubers-atraem-5-milhoes-para-aulas-fora-da-escola,70003105993. Acesso em: 28 nov. 2019.

CASTELLS, Manuel. A sociedade em rede. v. 1. São Paulo: Paz e Terra, 2002.

ESCOSTEGUY FILHO, João Carlos. Batalhas públicas pela história nas redes sociais: articulações para uma educação histórica em direitos humanos. Revista História Hoje, v. 8, n. 15, p. 39-65, 2019.

FOSTER, Meg. Online and Plugged in? Public History and Historians in the digital age. Public History Review, v. 21, p. 1-19, 2014.

FRISCH, Michael. A história pública não é uma via de mão única, ou, De $A$ Shared Authority à cozinha digital, e vice-versa. In: MAUAD, Ana Maria; ALMEIDA, Juniele R. de; SANTHIAGO, Ricardo. História pública no Brasil: Sentidos e itinerários. São Paulo: Letra e Voz, 2016. p. 57-69. 
FRISCH, Michael. A Shared Authority: Essays on the Craft and Meaning of Oral and Public History. Albany: State University of New York Press, 1990.

HERMETO, Miriam. Podem os palcos ser lugares de história pública? In: BORGES, Viviane T.; MAUAD, Ana Maria; SANTHIAGO, Ricardo (org.). Que história pública queremos? São Paulo: Letra e Voz, 2018.

LEVY, Pierre. Cibercultura. São Paulo: Ed. 34, 1999.

MARQUES, Fabrício. Microfones abertos para a ciência. Pesquisa Fapesp, n. 277, mar. 2019. Disponível em: https://revistapesquisa.fapesp.br/2019/03/14/microfones-abertos-para-a-ciencia/. Acesso em: 25 nov. 2019.

MARTINS, Lara B.; ZERBINI, Thaís. Escala de estratégias de aprendizagem: evidências de validade em contexto universitário híbrido. Psico-USF, Bragança Paulista, v. 19, n. 2, p. 317-328, maio/ago. 2014.

MORIN, Edgar. Ciência com consciência. Rio de Janeiro: Bertrand Brasil, 2000.

ROSANVALLON, Pierre. Parlamento dos invisíveis. São Paulo: Annablume, 2014.

ROUSSO, Henry. Rumo a uma globalização da memória. História Revista: revista da Faculdade de História e do Programa de Pós-Graduação em História, v. 19, n. 1, p. 265-279, 2014.

RÜSEN, Jörn. História Viva. Teoria da História III: formas e funções do conhecimento histórico. Brasília: Ed. UnB, 2007.

SARLO, Beatriz. Tempo passado: cultura da memória e guinada subjetiva. São Paulo: Companhia das Letras; Belo Horizonte: Ed. UFMG, 2007.

\section{NOTAS}

${ }^{1}$ Disponível em: https://www.dell.com/learn/br/pt/en/press-releases/2017-07-24-dell-technologies-impact-of-new-technologies-on-society. Acesso em: 25 nov. 2019.

${ }^{2}$ Disponível em: https://www.thinkwithgoogle.com/intl/pt-br/advertising-channels/ v\%C3\%ADdeo/creators-connect-o-poder-dos-youtubers/. Acesso em: 25 nov. 2019.

3 "conjunto de competências de interpretação do mundo e de si próprio, que articula o máximo de orientação do agir com o máximo de autoconhecimento, possibilitando assim o máximo de auto realização ou de reforço identitário" (RÜSEN, 2007, p. 95).

${ }^{4}$ Disponível em: https://www.youtube.com/watch?v=qtLMPoWa5kE. Acesso em: 28 nov. 2019.

${ }^{5}$ Disponível em: https://ameripoppins.blogspot.com/. Acesso em: 25 nov. 2019.

${ }^{6}$ Disponível em: https://www.instagram.com/heyall_africa/. Acesso em: 24 nov. 2019.

${ }^{7}$ Disponível em: https://twitter.com/africa_historia. Acesso em: 27 nov. 2019. 
${ }^{8}$ Disponível em: https://www.facebook.com/afrixcinema. Acesso em: 27 nov. 2019.

9 Disponível em: https://www.youtube.com/channel/UCcP5jAFYYlhD7YZIicBXfPA. Acesso em: 27 nov. 2019.

10 Disponível em: https://castbox.fm/channel/Ra\%C3\%ADzes-de-Baob\%C3\%A1id2316329? country=br. Acesso em: 27 nov. 2019.

${ }^{11}$ Disponível em: https://www.youtube.com/watch?v=Rq2igNmMnC0. Acesso em: 27 nov. 2019.

${ }^{12}$ Disponível em: https://thefirstblackwomanto.tumblr.com/. Acesso em: 27 nov. 2019.

${ }^{13}$ Disponível em: https://open.spotify.com/show/2DDTkeVizfIr4EVSICflGN?si=yTWmZ AxoQL66OY62U0J1zw. Acesso em: 27 nov. 2019.

${ }^{14}$ Disponível em: https://www.youtube.com/watch?time_continue=479\&v=xue87of7pZE\& feature=emb_logo. Acesso em: 27 nov. 2019.

${ }^{15}$ Disponível em: https://soundcloud.com/user-939348583/nbadunk. Acesso em: 27 nov. 2019.

${ }^{16}$ Disponível em: https://soundcloud.com/estefani-607707983. Acesso em: 27 nov. 2019.

${ }^{17}$ Um conjunto de atividades teórico-práticas vivenciadas pelos alunos para formação da sua identidade profissional, sob orientação e acompanhamento docente.

${ }^{18}$ Disponível em: https://twitter.com/MedievandoH. Acesso em: 27 nov. 2019.

${ }^{19}$ Disponível em: https://www.youtube.com/channel/UCcmNciNAt6wRhHrRD-PeU_w?fb clid=IwAR0KXXVVvdTEjHLcDXwPsN5DeGs1gRSJNS7SuVpN-VzOQF_g2Law6gqBDeU. Acesso em: 27 nov. 2019.

${ }^{20}$ Disponível em: https://www.facebook.com/medievandouftmturmaxvii/?redirect=false. Acesso em: 30 nov. 2019.

21 Disponível em: https://www.instagram.com/nobrecurioso/?fbclid=IwAR2TX_ DSk1 etRhYdf7HqsCAg0GL2pvzkLOLYxEtlQsqhCcdfUeHCAOyORyU. Acesso em: 30 nov. 2019.

${ }^{22}$ Disponível em: https://www.instagram.com/barbaridadesmedievais/?hl=pt-br. Acesso em: 30 nov. 2019.

${ }^{23}$ Algo semelhante a isso foi feito ao final da disciplina de História dos EUA em 2018, com a elaboração de um site: https://usainmedias.wixsite.com/usamedia.

${ }^{24}$ Sobre os novos campos de atuação profissional para o licenciado em história ver as matérias de Renata Cafardo para editorial de Educação do jornal O Estado de S. Paulo e, também, de Fabrício Marques para a revista Pesquisa Fapesp (CAFARDO, 2019; MARQUES, 2019).

Artigo recebido em $1^{\circ}$ de dezembro de 2019. Aprovado em 4 de dezembro de 2019. 